\title{
The Development and Psychometric Validation of the Japanese Version of the Home Healthcare Nurses' Job Satisfaction: A Cross-Sectional Study Among Japanese Home Healthcare Nurses
}

Yoko MORI ( $\nabla$ morikanr@tmd.ac.jp )

Tokyo Medical and Dental University

Miki SASAKI

Tokyo Medical and Dental University

Yasuko OGATA

Tokyo Medical and Dental University

Taisuke TOGARI

The Open University of Japan

\section{Research Article}

Keywords: home healthcare nurses, job satisfaction, Japanese version, scale development, reliability, validity

Posted Date: September 16th, 2021

DOI: https://doi.org/10.21203/rs.3.rs-841900/v1

License: () (1) This work is licensed under a Creative Commons Attribution 4.0 International License. Read Full License 


\section{Abstract}

Background: High-quality and attractive work environments and nurses' intention to stay are highly related to the job satisfaction of home healthcare nurses. Accordingly, a reliable and valid tool is required to assess home healthcare nurses' job satisfaction for evaluating and improving the work environment and clinical practice of home healthcare. This study aimed to develop and examine the Japanese version of the Home Healthcare Nurses' Job Satisfaction Scale (HHNJS-J).

Methods: The Home Healthcare Nurses' Job Satisfaction Scale (HHNJS) was translated into Japanese, and a backward-translation was performed until equivalence between the original and backward-translated the HHNJS was confirmed. Subsequently, a mail survey was conducted among 409 home healthcare nurses from 154 home healthcare agencies in Japan. We evaluated construct validity through confirmatory factor analysis (CFA), and criterion-related validity and internal consistency were also tested.

Results: The CFA revealed, a second-order seven-factor structure and adequate internal consistency, although, the fit of the data to the factor structure was moderate. As per the goodness-of-fit indices of the final model of the CFA, the comparative fit index was 0.89 and root mean square error of approximation was 0.06 . This newly translated scale can be used to assess the job satisfaction of home healthcare nurses within Japan.

Conclusions: The HHNJS-J evaluated acceptable reliability and validity among Japanese home healthcare nurses and had application in clinical practice in Japan.

\section{Background}

With the aging population, the need for healthcare delivery is also increasing. Especially in developed countries, the mode of healthcare delivery is shifting from hospitals to community-based care $[1,2]$. With this change, the medical care provided to older adults is becoming more sophisticated, and there is a greater need for high-quality home healthcare services to support community medical care [3].

In this context, to retain and increase human resources within the community, an attractive nursing practice environment is necessary. Home healthcare nurses' job satisfaction are highly associated with the quality and attractiveness of work environments and nurses' intention to stay [4-6]. For over a century now, the concept of job satisfaction has been highlighted in the existing literature. Over the last two decades, the awareness regarding job satisfaction has been growing within international nursing research and practice [7]. Moreover, it has proven valuable for healthcare organizations as increased job satisfaction can improve nursing productivity and patient outcomes [8, 9]. However, the current literature on home healthcare nurses' job satisfaction is limited [10-15]. Furthermore, most of the existing studies have been conducted among nurses working in acute care setting [6]. If the actual conditions of home healthcare agencies can be assessed by evaluating the workplace environments for home healthcare nurses, it will help in the formulation of measures to retain them in a community-based setting.

Despite the limited existing literature, a scale has been developed to measure job satisfaction among home healthcare nurses. Modifications to improve internal consistency have been made by Ellenbecker, Byleckie, \& Samia [16] and they have further emphasized the need for reliable, valid, and useful tools.

The Home Healthcare Nurses' Job Satisfaction Scale (HHNJS) [16] was developed after multiple modifications. Scale development was initiate in 1998, and the main milestones are described here.

The first study was conducted with a sample of 340 home healthcare nurses in 2005 . From this study emerged the original 30 -item HHNJS, which comprises nine factors-five intrinsic and four extrinsic characteristics-of job satisfaction. However, the results indicated areas for further refinement of the HHNJS. Reliability was $<0.70$ for five of the nine subscales and one subscale consisted of only two items $[11,17]$.

Based on these results, the researchers conducted another study to enhance the internal consistency of the HHNJS subscales through item refinement and examined the conceptual grouping of subscales into intrinsic and extrinsic characteristics of job satisfaction. As a result, five items were added to the revised version, which had low alpha scores, and four items were revised. 
Next, a sample of 2,274 home healthcare nurses was examined using the revised version of the HHNJS. The revised HHNJS differed in two ways. First, two subscales, "autonomy in work scheduling" and "autonomy of work activities," were combined into a single subscale named "autonomy and control." Second, the assignment of subscales to categories was changed. The utility of distinguishing between the intrinsic and extrinsic factors of job satisfaction for home healthcare nurses was limited, as the work environment greatly affected the factors comprising job satisfaction. The final HHNJS was composed of 30 items across eight subscales (see Additional file 1). The estimated internal consistency reliability of six of the eight subscales improved [16].

Thus, the creation of a Japanese version of the scale is highly significant because it will be used to measure the job satisfaction of home healthcare nurses in Japan, and the results can be used to improve nursing environments and practice in the country. Our study aimed to confirm the reliability and validity of the Japanese version of the HHNJS (HHNJS-J).

\section{Methods}

\section{Design}

This study employed a cross-sectional descriptive design.

\section{Participants and survey methodology}

A total of 409 Japanese home healthcare nurses participated in this study. The inclusion criteria were home healthcare nurses who had been employed for more than 6 months by homecare agencies. The sample was recruited in two phases. First, we sent study cooperation requests to homecare agencies that were regular members of the National Association for Visiting Nurse Service in metropolitan areas including Tokyo. We then confirmed the number of copies of the questionnaire to be mailed with the agencies that agreed to cooperate in the study. Second, we sent the number of questionnaires requested to the homecare agency with an agreement for study cooperation. The selection was conducted from February to June 2020.

\section{Development of the HHNJS-J}

The original 30-item English scale was translated into Japanese. The following five steps were followed. First, we gained permission to translate and use the HHNJS from the original author and the publisher. Next, the principal researcher of our study, who has experience in home healthcare nursing, carried out an independent translation of the HHNJS from English to Japanese. Second, in the reconciliation phase, seven researchers, including two experienced home healthcare nurses, met face-to-face and reached a consensus on a draft of the Japanese translation of the HHNJS that best reflected literal and conceptual equivalence with the English instrument. Third, in the backward translation phase, a professional translator, who is a native English speaker without knowledge of the original HHNJS, back-translated the Japanese version into English. Fourth, in the back translation review and harmonization phase, the same seven researchers met face-to-face and reviewed the back-translation to ensure it was conceptually equivalent to the original. In the final phase, which entailed cognitive debriefing and finalization, two researchers with experience in home healthcare nursing tested the pre-final Japanese version of the HHNJS to confirm whether the items were subjectively relevant and appropriate to the situation of home healthcare nurses' job satisfaction. The original author also confirmed the cognitive equivalence of the translated HHNJS-J.

\section{Measurements}

The questionnaire consisted of the HHNJS-J and an instrument to measure job satisfaction in Japanese nurses to evaluate criterionrelated validity. We also collected information regarding the participants' demographic characteristics.

\section{HHNJS-J}

The questionnaire included 30 items across eight subscales. Items such as "Patients are satisfied with the care that I provide" were rated on a 5-point Likert scale ranging from 1 (strongly disagree) to 5 (strongly agree). The total score ranged from 30 to 150 , with higher scores indicating greater job satisfaction. Five negatively worded items were reverse scored.

\section{Job Satisfaction in Japanese Nurses Questionnaire}


Nurses' job satisfaction was also assessed using the 25-item Job Satisfaction in Japanese Nurses Questionnaire [18, 19], where higher scores indicated greater satisfaction. Items such as "I have confidence as a nurse" were rated on a 5-point Likert scale ranging from 1 (strongly disagree) to 5 (strongly agree). The total score ranged from 25 to 125 . This scale was reliable with a Cronbach's alpha of 0.87 for the overall scale.

\section{Demographic variables}

The demographic variables included age, gender, work status, educational background, period of working as a clinical nurse, period of working as a home healthcare nurse, family constitution of the person who required caregiving, and number of minor children.

\section{Statistical analysis}

Regarding participant characteristics, the proportion of categorical variables and mean, standard deviation, ceiling effect, and floor effect of each item was calculated [20].

Confirmatory factor analysis (CFA) was performed to test the fit of the data to the factor structure. We performed CFA on the same construct as the original scale, but with several modifications to make the path diagram more faithful to the data extracted from Japanese home healthcare nurses. As a result of the modification, four models were created: (1) a second-order eight-factor model: original HHNJS hypothesis model; (2) a second-order eight-factor model: model with changed affiliations; (3) a second-order sevenfactor model; and (4) a second-order seven-factor model with an item deleted. Model fit was assessed using a combination of indices, which included the goodness of fit index (GFI), comparative fit index (CFI), Tucker-Lewis index (TLI), and root mean square error of approximation (RMSEA). For the first two indicators, values $>0.90$ were considered adequate [21-23], with a preference for values $>$ 0.95 [24]. For the RMSEA index, values $\leq 0.05$ indicated the best fit [25], although values between 0.05 and 0.08 indicated a reasonable fit $[26,27]$.

Pearson's product-moment correlation coefficients were examined between the total Job Satisfaction in Japanese Nurses Questionnaire score as an external criterion and the total score and score for each subscale of a second-order seven-factor model with an item deleted to evaluate criterion-related validity.

Cronbach's alpha was calculated for a second-order seven-factor model with an item deleted to assess internal consistency. Alpha coefficients $\geq 0.70$ were considered satisfactory [28].

All statistical analyses, except for the CFA, were performed using SPSS 26 for Windows (IBM Corp., Armonk, NY, USA). CFA was conducted using AMOS version 26 for Windows (Chicago, IL; IBM SPSS Statistical Programs). Statistical significance was set at $p$ $<.05$.

\section{Ethical considerations}

This study was approved by the institutional review board of the concerned institution (approval number: M2019-290). All participants were informed about the purpose of the study and the confidentiality of the data collected, after which they provided written informed consent.

\section{Results}

\section{Sample characteristics}

A total of 154 homecare agencies responded to the study cooperation requests (response rate $=7.7 \%$ ) and 446 respondents returned the questionnaire (response rate $=53.4 \%$ ). Of these, 37 respondents were excluded because of incomplete answers to the HHNJS-J or Job Satisfaction in Japanese Nurses Questionnaire. The remaining 409 responses were included in the analysis. The sociodemographic characteristics of the respondents are shown in Table 1. 
Participants' Sociodemographic Characteristics $(n=409)$

\begin{tabular}{|c|c|c|}
\hline Variables & n (Mean) & $\%(S D)$ \\
\hline \multicolumn{3}{|l|}{ Gender } \\
\hline Women & 393 & 96.1 \\
\hline Men & 15 & 3.7 \\
\hline Missing & 1 & 0.2 \\
\hline \multicolumn{3}{|l|}{ Age (Years) } \\
\hline$<30$ & 23 & 5.6 \\
\hline$<40$ & 70 & 17.1 \\
\hline$<50$ & 150 & 36.7 \\
\hline$<60$ & 133 & 32.5 \\
\hline$\geqq 60$ & 32 & 7.8 \\
\hline Missing & 1 & 0.2 \\
\hline \multicolumn{3}{|c|}{ Period of working as a clinical nurse (Years) } \\
\hline$<1$ & 1 & 0.2 \\
\hline$<5$ & 33 & 8.1 \\
\hline$<10$ & 70 & 17.1 \\
\hline$<20$ & 134 & 32.8 \\
\hline$\geqq 20$ & 169 & 41.3 \\
\hline Missing & 2 & 0.5 \\
\hline \multicolumn{3}{|l|}{ Educational background } \\
\hline Vocational school & 284 & 69.5 \\
\hline Junior college & 37 & 9.0 \\
\hline Bachelor's degree or higher & 63 & 15.4 \\
\hline Others & 24 & 5.9 \\
\hline Missing & 1 & 0.2 \\
\hline \multicolumn{3}{|c|}{ Period of working as a home healthcare nurse (Years) } \\
\hline$<1$ & 30 & 7.3 \\
\hline$<5$ & 154 & 37.6 \\
\hline$<10$ & 92 & 22.5 \\
\hline$<20$ & 132 & 32.3 \\
\hline Missing & 1 & 0.2 \\
\hline \multicolumn{3}{|l|}{ Work status } \\
\hline Full-time & 294 & 71.9 \\
\hline Part-time & 114 & 27.9 \\
\hline Missing & 1 & 0.2 \\
\hline
\end{tabular}




\begin{tabular}{|llc|}
\hline Variables & $\mathbf{n}$ (Mean) & \% (SD) \\
\hline Family constitution & & \\
\hline Alone & 53 & 13.0 \\
\hline Living with families requiring caregiving or who have minor children & 192 & 46.9 \\
\hline Living separately from families requiring caregiving or who have minor children & 163 & 39.9 \\
\hline Missing & 1 & 0.2 \\
\hline HHNJS-J: Model 4 & $(93.4)$ & {$[12.1]$} \\
\hline Job Satisfaction in Japanese Nurses Questionnaire & $(89.2)$ & {$[11.5]$} \\
\hline HHNJS-J: Japanese version of the Home Healthcare Nurses' Job Satisfaction Scale; SD: Standard Deviation \\
\hline
\end{tabular}

The majority of the participants were women (393, 96.1\%). Further, 150 participants were in their 40 s (36.7\%), $41 \%$ had a clinical experience of over 20 years, $13 \%$ lived alone, and $47 \%$ lived with families who needed caregiving or had underage children. The mean total HHNJS-J score was 93.4 (standard deviation $=12.1$, range: $26-130$ ). None of the items demonstrated a ceiling or floor effect (Table 2). 
Means, Standard Deviations, Ceiling Effects, Floor Effects, and Cronbach's Alphas for HHNJS-J and Model 4 ( $\mathrm{n}=409$ )

\section{Items of HHNJS-J Model $4(a=.91)$ and factors with Cronbach's alphas}

Ceiling

effect

\section{Relationship with patients $(\mathrm{a}=.81)$}

1 Patients are satisfied with the care that I provide.

$\begin{array}{llll}3.64 & 0.59 & 4.23 & 3.05\end{array}$

2 The relationships I have built with patients are valuable.

$\begin{array}{llll}3.99 & 0.51 & 4.49 & 3.48\end{array}$

3 I am helping to maintain or improve patients' quality of life.

$\begin{array}{llll}3.97 & 0.45 & 4.42 & 3.52\end{array}$

$4 \quad$ My job is important and fulfilling.

$\begin{array}{llll}4.08 & 0.70 & 4.77 & 3.38\end{array}$

5 The patient care that I provide conforms to professional standards (ethical norms and accountability).

24 I can carry out every task that my job requires.

$\begin{array}{llll}3.97 & 0.54 & 4.51 & 3.43\end{array}$

Relationship with colleagues $(\mathrm{a}=.90)$

6 Being able to get support from my colleagues is a good aspect of my job.

\begin{tabular}{llll}
4.13 & 0.62 & 4.74 & 3.51 \\
\hline 4.14 & 0.68 & 4.81 & 3.46 \\
\hline 4.09 & 0.72 & 4.80 & 3.37 \\
4.17 & 0.72 & 4.89 & 3.46
\end{tabular}

7 I am getting along with the nurses with whom I work.

3.57

$0.73 \quad 4.31$

2.84

8 I have a cooperative relationship with the nurses with whom I work.

9 I have colleagues whom I can trust and rely on.

\section{Professional pride $(a=.86)$}

10 If I were to choose my specialty again, I would probably choose home health nursing.

11 I would like to recommend my job to other health professionals.

12 I speak with pride when I discuss my job with others.

\begin{tabular}{|llll}
\hline 3.66 & 1.04 & 4.70 & 2.62 \\
\hline 3.69 & 0.94 & 4.63 & 2.75 \\
\hline 3.95 & 0.86 & 4.80 & 3.09 \\
\hline
\end{tabular}

\section{Relationship with doctors $(a=.81)$}

13 Doctors respect my opinions regarding home care patients.

\begin{tabular}{llll}
3.42 & 0.79 & 4.20 & 2.63 \\
\hline 3.26 & 0.85 & 4.12 & 2.41
\end{tabular}

14 Doctors treat me as a colleague, a nursing specialist.

\section{Relationship with institution ( $a=.76)$}

15 I am content with the professional relationship that we have with the nurse administrator of this facility.

$\begin{array}{llll}3.56 & 0.90 & 4.46 & 2.65\end{array}$

16 I have some influence on organizational policy changes at this facility.

$\begin{array}{llll}2.92 & 1.05 & 3.97 & 1.87\end{array}$

17 I have the opportunity to develop skills that will advance my nursing expertise at this facility.

25 I can handle the growing demand for documentation in home health nursing.

3.49

3.49

0.89

4.38

2.60

\section{Autonomy and control ( $a=.78)$}

18 I can adjust my working hours if necessary.

3.65

3.22

0.80

4.02

19 I can change my working hours more flexibly than other clinical nurses.

$\begin{array}{llll}3.53 & 0.99 & 4.52 & 2.54\end{array}$

20 I can adequately manage my time outside of work.

$\begin{array}{llll}3.45 & 0.93 & 4.39 & 2.52\end{array}$

21 I independently make important decisions in my daily work.

$\begin{array}{lll}3.64 & 0.84 & 4.47\end{array}$

2.80

\section{Salary and benefits $(a=.62)$}

27 I am satisfied with my current salary.

$2.84 \quad 1.09 \quad 3.92$

1.75 


\begin{tabular}{|c|c|c|c|c|c|}
\hline \multicolumn{2}{|r|}{ Items of HHNJS-J Model $4(a=.91)$ and factors with Cronbach's alphas } & \multirow{2}{*}{$\begin{array}{l}\text { Mean } \\
2.52\end{array}$} & \multirow{2}{*}{$\begin{array}{l}\text { SD } \\
0.96\end{array}$} & \multirow{2}{*}{$\begin{array}{l}\begin{array}{l}\text { Ceiling } \\
\text { effect }\end{array} \\
3.47\end{array}$} & \multirow{2}{*}{$\begin{array}{c}\begin{array}{l}\text { Floor } \\
\text { effec }\end{array} \\
1.56\end{array}$} \\
\hline 28 & The pay scale at this facility needs improvement. & & & & \\
\hline 30 & I am satisfied with the employee benefits provided at this facility. & 2.85 & 1.02 & 3.87 & 1.84 \\
\hline
\end{tabular}

\section{Structure of the HHNJS-J}

The following four-factor analysis models were specified and compared.

Model 1: Second-order eight-factor model: original HHNJS hypothesis model

First, a second-order eight-factor model was tested. This model included all 30 items of the original HHNJS hypothesis model. However, this model showed a relatively poor fit with the data. The standardized path coefficients of items 24 and 25 (stress and workload) were 0.00 and -0.05 , respectively, and both items showed no significant differences. Furthermore, the standardized path coefficient of item 29 (salary and benefits) was -0.06 and showed no significant difference. After releasing two error term covariances based on the largest and second largest modification indices, the model fit indices were $\mathrm{CFI}=0.845, \mathrm{GFI}=0.835, \mathrm{TLI}=$ 0.829, and RMSEA $=0.073$ [95\% confidence interval ( $\mathrm{Cl}$ ): 0.068-0.077] (Table 3). In this model, the strongest error term covariance occurred between items 24 and 25, both of which were related to stress and workload. The other strong error term covariance was between items 28 and 29 , both of which were related to salary and benefits.

Table 3

Confirmatory Factor Analysis: Comparison of Several Indices from Models 1 to $4(n=409)$

\begin{tabular}{|lcccc|}
\hline Model & CFI & GFI & TLI & RMSEA \\
\hline Model 1: Second-order eight-factor model: original HHNJS hypothesis model & 0.85 & 0.84 & 0.83 & 0.07 \\
\hline Model 2: Second-order eight-factor model: model with changed affiliations & 0.88 & 0.85 & 0.87 & 0.06 \\
\hline Model 3: Second-order seven-factor model & 0.88 & 0.85 & 0.87 & 0.06 \\
\hline Model 4: Second-order seven-factor model: model with an item deleted & 0.89 & 0.85 & 0.87 & 0.06 \\
\hline CFI: comparative fit index; GFI: goodness of fit index; TLI: Tucker-Lewis index; RMSEA: root mean square error of approximation \\
\hline
\end{tabular}

Model 2: Second-order eight-factor model: a model with changed affiliations

Next, a second-order eight-factor model was tested, according to the results of Model 1 . We changed the affiliation factors attributed to items 24 and 25 according to the factor loadings of the exploratory factor analysis. Item 24 changed affiliation to the "relationship with patients" factor; thus, its standardized path coefficient improved from 0.00 to 0.61 , which resulted in a significant difference. Likewise, item 25 changed affiliation to the "relationship with institution" factor; thus, its standardized path coefficient improved from -0.05 to 0.49 , which resulted in a significant difference. After releasing two error term covariances, based on the largest and second largest modification indices, the model fit indices were $\mathrm{CFI}=0.877, \mathrm{GFI}=0.849, \mathrm{TLI}=0.865$, and RMSEA $=0.064[95 \% \mathrm{Cl}: 0.060-0.069]$ (Table 3).

In this model, the strongest error term covariance occurred between items 24 and 25, both of which were related to stress and workload. The other strong error term covariance was between items 28 and 29, both of which were related to salary and benefits. These results were the same as in Model 1.

\section{Model 3: Second-order seven-factor model}

Next, a second-order seven-factor model was tested, according to the results of Model 2. Path coefficients between first-order; "job satisfaction" and second-order; "stress and workload" were 0.00 , which implies no connection at all. Hence, we removed "stress and workload" from the factors, which means that it generated a seven-factor structure. After releasing two error term covariances based on the largest and second largest modification indices, the model fit indices were $\mathrm{CFI}=0.877, \mathrm{GFI}=0.849, \mathrm{TLI}=0.865$, and RMSEA $=$ 0.064 [95\% Cl: $0.060-0.069$ ] (Table 3). In this model, the strongest error term covariance occurred between items 24 and 25 , both of 
which were related to stress and workload. The other strong error term covariance was between items 28 and 29 , both of which were related to salary and benefits. These results are the same as those in Models 1 and 2.

After examining the four CFA models, Model 4 was adopted because it showed the most improvement in the model fit of the results.

Model 4: Second-order seven-factor model: model with one item deleted

It was notable that the second-order seven-factor model served as a boundary model for the viability of the more elaborate model. One thing that remained an issue was the path coefficient of item 29 (stress and workload), which was -0.06 . Therefore, this item was deleted.

After releasing two error term covariances based on the largest and second largest modification indices, the model fit indices were CFI $=0.885, \mathrm{GFI}=0.853, \mathrm{TLI}=0.873$, and RMSEA $=0.064$ [95\% Cl: 0.060-0.069] (Table 3 ). In this model, the strongest error term covariance occurred between items 24 and 25, both of which were related to stress and workload. The other strong error term covariance was between items 4 (relationship with patients) and 12 (professional pride); this result differed from those of the other models.

As demonstrated by these results, while we remained faithful to the structure of the original scale, we made modifications based on the results of our data. Thus, Model 4 was proposed (Fig. 1).

\section{Criterion-related validity of the HHNJS-J: Model 4}

The correlations between the total score of the HHNJS-J: Model 4, as well as the scores of the individual factor; relationship with patients, colleagues, doctors, and institution; professional pride; autonomy and control; and salary and benefits were significantly positively correlated with the scores on Job Satisfaction in Japanese Nurses Questionnaire (Table 4).

Table 4

Pearson's Correlation Coefficients for Model $4(n=409)$

\begin{tabular}{|c|c|c|c|c|c|c|c|c|}
\hline & \multicolumn{8}{|c|}{ Pearson's correlation coefficient } \\
\hline & $\begin{array}{l}\text { HHNJS- } \\
\mathrm{J} \text { total }\end{array}$ & $\begin{array}{l}\text { Relationship } \\
\text { with } \\
\text { patients }\end{array}$ & $\begin{array}{l}\text { Relationship } \\
\text { with } \\
\text { colleagues }\end{array}$ & $\begin{array}{l}\text { Professional } \\
\text { pride }\end{array}$ & $\begin{array}{l}\text { Relationship } \\
\text { with doctors }\end{array}$ & $\begin{array}{l}\text { Relationship } \\
\text { with } \\
\text { institution }\end{array}$ & $\begin{array}{l}\text { Autonomy } \\
\text { and } \\
\text { control }\end{array}$ & $\begin{array}{l}\text { Salary } \\
\text { and } \\
\text { benefits }\end{array}$ \\
\hline $\begin{array}{l}\text { Job } \\
\text { Satisfaction } \\
\text { in Japanese } \\
\text { Nurses } \\
\text { Questionnaire }\end{array}$ & $0.847 \star \star$ & $0.648^{\star \star}$ & $0.590 * *$ & $0.614^{\star \star}$ & $0.603^{\star *}$ & 0.691 ** & $0.615^{\star \star}$ & $0.472^{\star *}$ \\
\hline
\end{tabular}

Reliability of the HHNJS-J: Model 4

The Cronbach's alpha coefficients of the total HHNJS-J and each factor is shown in Table 2. Cronbach's alpha of the total HHNJS-J was 0.91 . Cronbach's alpha coefficients of the seven factors were: 0.81 (relationship with patients), 0.90 (relationship with colleagues), 0.86 (professional pride), 0.81 (relationship with doctors), 0.76 (relationship with institution), 0.78 (autonomy and control), and 0.62 (salary and benefits).

\section{Discussion}

This study evaluated the reliability and validity of the HHNJS-J among home healthcare nurses. This is the first study to use the HHNJS to assess home healthcare nurses' job satisfaction in Japan.

The results of the CFA to test the fit of the data to the factor structure revealed moderate structural validity. Among the four models, Model 4 was a better fit than Models 1 to 3 . In this study, the difference between the original scale and the HHNJS-J in the factor structure is based on cross-cultural and other differences among the participants. The item "salary at other facilities is higher than at this one," included in factor seven of "salary and benefits," was consequently deleted. This item indicated a higher interest in income. 
However, studies on home healthcare nurses in Japan have shown that although they felt their wages were low, communicating with clients was highly valued [29]. The results of this study suggested that income was not significantly associated with job satisfaction among home healthcare nurses in Japan. Alternatively, the satisfaction of home healthcare nurses outside of Japan has been linked to stable and high income, with greater satisfaction associated with salary and benefits, which has been reported to have a positive correlation with intent to remain employed [30].

The item "Sometimes, I experience stress from the fact that my duties are predetermined," included in the factor of "stress and workload," was also consequently deleted. In the US, autonomy and independence have been shown to be important for homecare nurses' job satisfaction [17]. Alternatively, home healthcare nurses in Japan do not require a high degree of independence. In a previous study, the factors that most influenced job satisfaction among home healthcare nurses in Japan were approval from clients and clients' families, and relationships within the workplace [31].

Although this scale was a faithful replication of the original, the results indicate the need to modify some items from a cross-cultural perspective. Thus, further studies are needed to investigate the construct of job satisfaction among home healthcare nurses in Japan.

\section{Limitations}

There are two main limitations to this study. First, generalizability is limited owing to the sampling method. Samples were collected only in metropolitan areas including Tokyo. Therefore, caution must be exercised in attempting to generalize the findings to different Japanese populations. Second, the degree of fitness of the CFA was insufficient. The cross-cultural differences between the original HHNJS and HHNJS-J may require elaboration of scale items and further research.

\section{Conclusion}

The results of this study, which examined the reliability and validity of the HHNJS-J, encourage and promote the use of this translated scale for home healthcare settings in Japan. These findings contribute to improve the levels of job satisfaction among home healthcare nurses.

\section{Abbreviations}

HHNJS: The Home Healthcare Nurses' Job Satisfaction Scale; HHNJS-J: Japanese version of the Home Healthcare Nurses' Job Satisfaction Scale; CFA: confirmatory factor analysis; GFI: the goodness of fit index, comparative fit index; CFI: comparative fit index; TLI: Tucker-Lewis index; RMSEA: root mean square error of approximation; 95\% Cl: 95\% confidence interval

\section{Declarations}

\section{Ethics approval and consent to participants}

This study was approved to the Ethics Committee of the Tokyo Dental and Medical University (approval number: M2019-290). Participants were provided with the study description and consent form via mail. They were asked to read the study description and provide informed consent before completing the questionnaire.

\section{Consent for publication}

Not applicable.

\section{Availability of data and materials}

The datasets used and/or analyzed during the current study are available from the corresponding author on reasonable request.

\section{Competing interests}

The authors declare that they have no competing interests.

\section{Funding}

Page 10/13 
This study was supported by JSPS KAKENHI (grant number 17K12493). The Funders had no role in the design of the study and collection, analysis, and interpretation of data and writing of the manuscript.

\section{Authors' contributions}

YM designed and conducted the study. YM was a major contributor in drafting the manuscript. TT guided statistical interpretation. YO, TT, and MS made substantial inputs to the revision of the study. All authors approved the final manuscript.

\section{Acknowledgments}

We would like to thank Dr. Carol Hall Ellenbecker for her permission to use the HHNJS and all the home healthcare nurses for their participation in this study.

\section{References}

1. Anderson GF, Hussey PS. Population aging: A comparison among industrialized countries. Health Aff (Project Hope). 2000;19(3):191-203. doi:10.1377/hlthaff.19.3.191

2. Johri M, Beland F, Bergman H. International experiments in integrated care for elderly: A synthesis of the evidence.Int $\mathrm{J}$ Geriatr Psychiatry. 2003;18:222-235. doi:10.1002/gps.819

3. Aylward S, Stolee P, Keat N, Johncox V. Effectiveness of continuing education in long-term care: A literature review. Gerontologist. 2003;43(2):259-271. doi:10.1093/geront/43.2.259

4. Tullai-McGuinness ST. Home healthcare practice environment: Predictors of RN satisfaction. Res Nurs Health. 2008;31:252-260. doi:10.1002/nur.20257

5. Ellenbecker CH, Porell EW, Samia L, Byleckie JJ, Milburn M. Predictors of Home Healthcare Nurse Retention. J Nurs Scholarsh. 2008;40(2)151-160.

6. Ellenbecker CH. Home Health Care Nurses' Job Satisfaction: A System Indicator. Home Health Care Manag Pract. 2001;13(6):462467.

7. Castaneda GA, Scanlan JM. Job satisfaction in nursing: A concept analysis. Nurs Forum. 2014;49(2):130-138.

8. Guleryuz G, Guney S, Aydin EM, Asan O. The mediating effect of job satisfaction and organizational commitment of nurses: A questionnaire survey. Int J Nurs Stud. 2008;45(11):1625-1635.

9. Kelly LA, McHugh MD, Aiken LH. Nurse outcomes in magnet and non-magnet hospitals. J Nurs Adm. 2012;42(10):428-433.

10. Anthony A, Milone-Nuzzo P. Factors attracting and keeping nurses in home care. Home Healthc. 2005;23(6):372-377.

11. Ellenbecker $\mathrm{CH}$, Byleckie JJ. Agencies make a difference in home healthcare nurses' job satisfaction. Home Healthc Nurse. 2005;23(12):777-786. doi:10.1097/00004045-200512000-00007

12. Lynch SA. Job satisfaction of home health nurses. Home Healthc Now. 1994;12(5):21-28.

13. Navaie-Waliser M, Lincoln P, Karuturi M, Reisch K. Increasing job satisfaction, quality care, and coordination in home health. J Nurs Adm. 2004;34(2):88-92.

14. Smith-Stoner M. Home care nurses' perception of agency and supervisory characteristics: Working in the rain. Home Healthc Now. 2004;22:536-546.

15. Tullai-McGuinness S, Madigan EA, Anthony MK. Exercise of autonomous home care: The relationship with the nurse. Home Healthc Now. 2005;23(6):378-384.

16. Ellenbecker $\mathrm{CH}$, Byleckie JJ, Samia LW. Further psychometric testing of the home healthcare nurse job satisfaction scale. Res Nurs Health. 2008;31(2):152-164. doi:10.1002/nur.20241

17. Ellenbecker $\mathrm{CH}$, Byleckie JJ. Home Healthcare Nurses' Job Satisfaction Scale: Refinement and psychometric testing.J Adv Nurs. 2005;52(1):70-78. doi:10.1111/j.1365-2648.2005.03556.x

18. Yamashita M. Job satisfaction in Japanese nurses. J Adv Nurs. 1995;22:158-164. doi:10.1046/j.1365-2648.1995.22010158.x

19. Yamashita M. Kangofu no shokumumannzoku ni kansuru kenkyu [A Study on Job Satisfaction of Nurses], kangokanri [in Japanese]. 1995;5(3):191-195. 
20. Mokkink LB, Terwee CB, Patrick DL, Alonso J, Statforf PW, Knol DL, et al. The COSMIN study reached international consensus on taxonomy, terminology, and definitions of measurement properties for health-related patient-reported outcomes. J Clin Epidemiol. 2010;63(7):737-45.

21. Bentler PM. Comparative fit indexes in structural models. Psychol Bull. 1990;107(2):238-246. doi:10.1037/00332909.107.2.238

22. Brown TA. Confirmatory factor analysis for applied research. $3^{\text {rd }}$ ed. New York: Guildford Press; 2006.

23. Kaariainen M, Kanste O, Elo S, Polkki T, Miettunen J, Kyngas H. Testing and verifying nursing theory by confirmatory factor analysis. J Adv Nurs. 2011;67:1163-1172.

24. Hu LT, Bentler PM. Cutoff criteria for fit indexes in covariance structure analysis: Conventional criteria versus new alternatives. Struct Equ Model. 1999;6(1):1-55. doi:10.1080/10705519909540118

25. Bagozzi R, Yi Y. On the evaluation of structural equation models. J Acad Mark Sci. 1988;16(1):74-94.

26. Green SB, Yang Y. Reliability of summed item scores using structure equation modeling: An alternative to coefficient alpha. Psychometrika. 2009;74(1):155-167. doi:10.1007/s11336-008-9099-3

27. Byrne BM. Structual equation modeling with AMOS: basic concepts, applications, and programming. Lawrence Erlbaum Associates Publishers; 2001.

28. Cortina JM. What is coefficient alpha? An examination of theory and applications. J Appl Psychol. 1993;78(1):98-104.

29. Hirakawa Y, Chiang C, Uemura M, Aoyama A. Job satisfaction among Japanese home-visit care workers. Home Health Care Manag Pract. 2019;31(1):3-8. doi:10.1177/1084822318803861

30. Tourangeau AE, Patterson E, Saari M, Thomson H, Cranley L. Work-related factors influencing home care nurse intent to remain employed. Health Care Manage Rev. 2017;42(1):87-97. doi:10.1097/HMR.0000000000000093

31. Tomioka S, Ishizawa M, Ohtake M, Akama A, Sato C, Suzuki I, et al. Factors related to job satisfaction of visiting nurses. J Jpn Acad Home Care [in Japanese]. 2007;11(1):43-51.

\section{Figures}




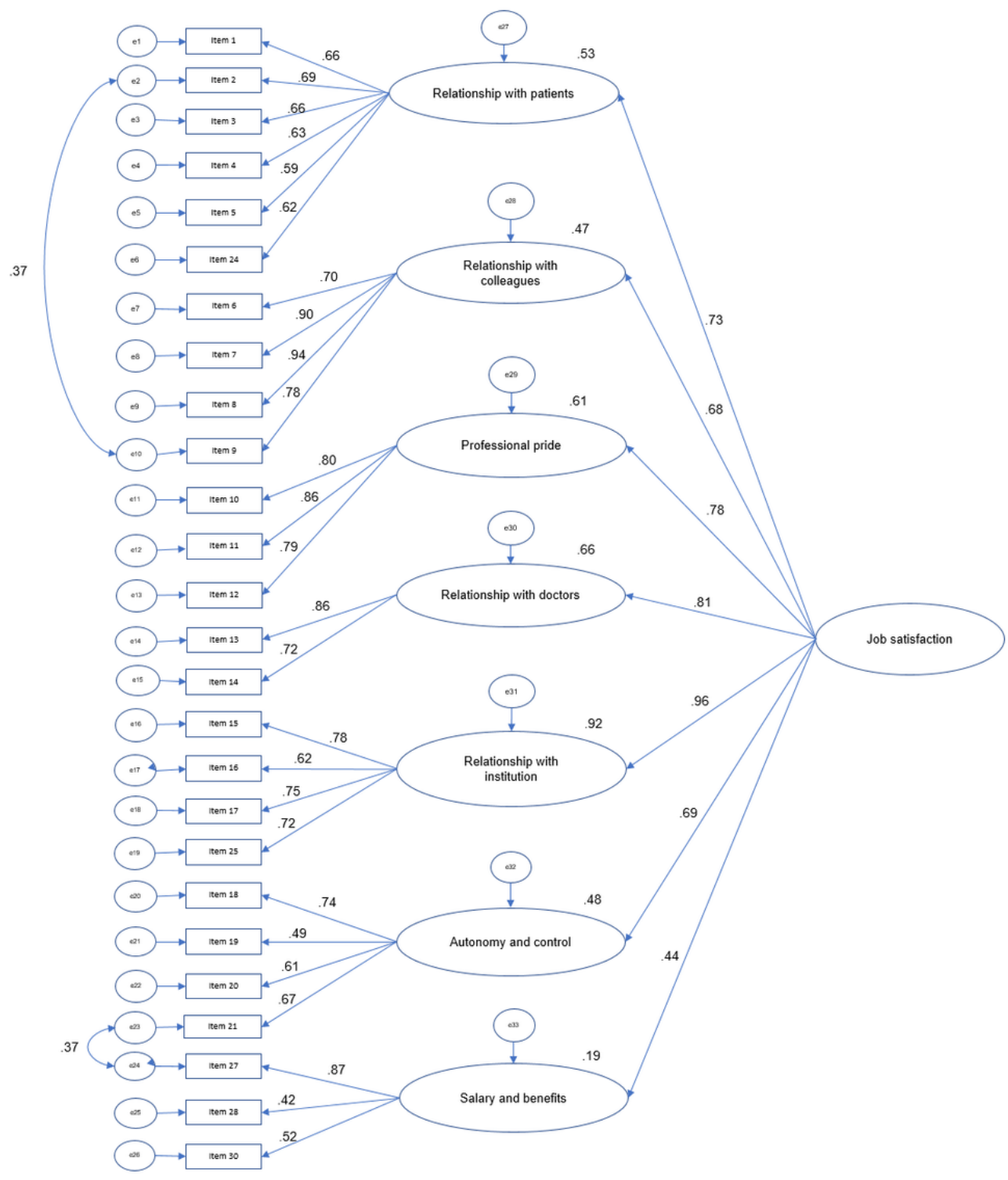

\section{Figure 1}

Confirmatory factor analysis of the HHNJS-J (Model 4) Model fit indices: Comparative fit index $=0.89$ Goodness of fit index $=0.85$ Tucker-Lewis index $=0.87$ Root mean square error of approximation $=0.06$ (95\% confidence interval: 0.060-0.069) HHNJS-J: Japanese version of the Home Healthcare Nurses' Job Satisfaction Scale

\section{Supplementary Files}

This is a list of supplementary files associated with this preprint. Click to download.

- 20210824SupplementaryInformation.xlsx 